\title{
Language Policy Research in East Asia: Global Challenges and Local Responses
}

\author{
Xuesong Gao ${ }^{1}$
}

Published online: 22 October 2016

(C) De La Salle University 2016

\section{Introduction}

The issue addressed in this collection of studies is the significant challenges facing language policy-makers and language educators emanating from dramatic cultural, demographic, economic, political, and social changes in global and East Asian contexts (e.g., Heller and MartinJones 2001; Block and Cameron 2002; Tollefson 2012; Tollefson and Tsui 2004; Park and Wee 2012). Traditionally, language policy-making has been largely driven by particular visions and aspirations of the political establishment and institutions in specific nations and contexts which in turn led to prescriptive pedagogical models and influenced language education practices in these contexts profoundly. The policy-making mechanisms and processes now have to consider not only the strategic need for enhancing global engagement and sustaining linguistic diversity but also increasingly complex demographic and socio-cultural realities in contexts where relevant language policies are to be implemented (e.g., Park and Wee 2012; Lo Bianco et al. 2009). In addition, the language policymaking process needs to accommodate increasingly strong bottom-up voices, by involving individuals in making decisions about what languages to learn and use with whom as well as when, why, and how these languages are used (e.g., Gao 2012, 2015). These shifts add substantially to complications of language policy-making and require major conceptual and methodological shifts in research in

Xuesong Gao

xsgao@hku.hk

1 Faculty of Education, The University of Hong Kong, Room 663, 6/F, Mengwah Complex, Hong Kong, China order to fully appreciate and address the rising challenges (Pérez-Milans 2015). This special issue highlights these significant challenges and invites readers to reflect on the possible responses that educational researchers could have in specific contexts.

The first challenge relates to the promotion of national standard and foreign languages in contexts characterized with linguistic diversity and dramatic demographic changes caused by internal and cross-border migrations. Over the years, national and regional governments in East Asian contexts have increasingly stressed the importance of English language competence for effective global engagement (e.g., Tollefson and Tsui 2004; Wang 2015; Yang and Zhang 2015). The continual rise of English as a strategically important language can undermine the use of mother tongue as medium of instruction, which is critical to the improvement of educational practices in many Asian contexts. In the meantime, promotion of national standard languages in Asian contexts such as China and Singapore has resulted in regional Chinese varieties or dialects being on the verge of disappearance because their usage is getting increasingly confined to private spaces (e.g., Gao 2012, 2015; Wee 2011).

The complexity of language policy-making is further exacerbated by societal individualization, because of which political establishments and institutions are unable to control, define, and regulate individuals' aspirations, desires, and identification (e.g., Yan 2010). In contrast, individuals are becoming more willing to challenge policy decisions through the media, especially social media and other public spaces. Individual voices have been rising and have started having impact because of institutions' neo-liberalization and marketization having resulted in shifts in relationships 
between individuals and political establishments and institutions (e.g., Piller and Cho 2013). Political establishments and institutions are partly easing regulation but are also recentralizing control of valuable resources and discursive space. They promote and manage individual personas through standardization of language skills and competence as aforementioned and evaluation of individual attainments right from schooling. Such shifts have had profound impact on language learners and teachers and have necessitated a methodological paradigm shift to be adopted in the relevant language policy research in many contexts including those in East Asia (e.g., Pérez-Milans 2015).

It must be noted that research on language policy-making has been dominated by grand policy narratives to capture how political establishments and institutions, responsible for top-down language policy-making, have been changing their understanding of socio-linguistic realities and reformulating the relevant policies. In recent decades, these institutions have felt the need to respond to gradually vocalizing individual demands about language policy-making. In the process, mass media has emerged as a critical broker between the public and governments with regard to the relevant language policies (see Gao 2015, in press; Shao and Gao in press). This shift draws attention to how these institutions manipulate individuals' perceptions of and attitudes toward particular language policies and how individuals manipulate other individuals' perceptions and attitudes, which constrain the policy alternatives for policy-makers and have profound impact on language policy-making.

\section{In This Special Issue}

Authors who have contributed to this special issue have taken up the challenge to explore how language policymakers, educators, and individuals have been responding to these challenges in various East Asian contexts. They report on various efforts that are largely related to

(1) initiatives to preserve and maintain linguistic diversity in the wake of standardization and promotion of languages at the national level;

(2) development and implementation of policy initiatives to support migrant population's integration into the mainstream of the society; and

(3) individual perceptions of and responses to various language policy initiatives, including those of language teachers, language learners, and other stakeholders, as well as the mediation of such perceptions and responses on policy development through mass media.

The lead article by De Costa, Park, and Wee is a conceptual piece that takes into consideration the neoliberal and commodification turn in language education. By exploring the interface between second-language acquisition and language planning and policy, De Costa, Park, and Wee put forward the notion of the linguistic entrepreneur, or 'an act of aligning with the moral imperative to strategically exploit language-related resources for enhancing one's worth in the world.' Citing examples from China, South Korea, and Singapore, they show how becoming a linguistic entrepreneur is increasingly being constructed as the responsibility of an ideal neoliberal subject. This has significant implications for language educators as they need to consider the historical and social backgrounds of learners and the emotional effects of language policies in practice. They also need to promote reflexive and critical awareness among learners, speaking directly to the need for designing language-in-education policies so that learning outcomes can be enhanced.

The three articles on Mainland China address three different challenges associated with the promotion of national languages (i.e., Chinese). Yu's study captures a key dilemma that the Chinese middle-class parents experienced when choosing between English or Chinese for their children's education as they encourage them to participate in 'Chanting Chinese Classics' classes, even though they were not aware that the national government has a policy to promote Chinese Classics Chanting. Yu's study nicely projects these middle-class parents' dilemma to the wider, ongoing oscillation between the nationalistic and international visions that the Chinese state has. Shen's paper draws attention to the fact that many regional Chinese varieties or dialects are at risk due to the promotion of national languages and dramatic socio-cultural changes caused by mass migration. He reports on how various stakeholders participated in the development of regional language policies to save the 'Shanghai dialect'. The study reveals the interaction between structural conditions such as power hierarchy and individual agency in mediating the development of the relevant policies. This raises the hope of an interactive and democratic dialogue for language policy-making even though such dialogue takes place within predefined policy constraints and the role of individual agency is quite limited. Wang and Curdt-Christiansen explore the enactment of The International Promotion of Chinese Policy (國際漢語推廣 政策) targeting international students in the Study in China program. By conducting a thorough analysis of policy documents, interviewing key individuals including students and teachers, and observing classes, they have identified conflicts between interests of different stakeholders at all levels, which constitute significant challenges in implementation of the policy at a mainland Chinese university. These conflicts undermine international students' experiences of learning Chinese, making it difficult for the Chinese State to realize the political objective of the Study in China program. 
Two studies examine the response to cross-border migration reflected in language policies of Japan and Korea. Otomo examines the need for a new language policy as a result of Japan's bilateral economic partnership agreement (EPA) with Southeast Asian countries. She contends that the pre-employment Japanese language training as stipulated by the relevant EPA policy documents is inadequate for migrant workers who come to Japan under the EPA arrangement and are expected to pass the national licensure examinations in Japanese if they wish to continue to work in Japan after the pre-determined period of time. Likewise, Lee problematizes the relevant language planning for North Korean refugees in South Korea. Through analyzing North Korean refugee students' narratives, he notes a discontinuity between the initial mandatory language support program and the optional continuing one. Relevant language support planning was also found to have failed to meet individual refugees' context-specific needs. Therefore, he concluded that the relevant language programs did not provide sufficient and practical support for the refugees.

In the three subsequent studies in Taiwan and Hong Kong, Lin and Yudaw focuses on one Truku (Indigenous) village in eastern Taiwan with an aim to understand the processes and possibilities of bottom-up language policy formation and implementation. Drawing on indigenous epistemology, this paper explores an alternative democratic and humanizing way of doing language policy and planning research to promote local knowledge, voice, and engagement. It discusses the complex and dynamic processes of collaboration and relationship building in developing bottom-up language revitalization initiatives and offers a more holistic and developmental understanding of the process by recognizing human relationships in praxis and featuring the affective dimension of language policy planning. Loh and Tam's paper explores how the alternative Chinese qualifications policy may affect social mobility of ethnic minorities in Hong Kong and how an alternative assessment framework can mediate the teaching and learning of Chinese as a second language. Through analyzing ethnic minority students' interview data, relevant surveys, and government documents, they conclude that alternative qualifications do not necessarily help improve ethnic minority students' social mobility since academic advancement is closely associated with their Chinese language proficiency. Therefore, what needs to be done is to undertake relevant policy and curriculum review based on recent demographic shifts and classroom realities so that teaching could be improved to help ethnic minority students acquire better Chinese language proficiency. Shao's analysis of 138 news articles published in Hong Kong print media on Putonghua as a medium of instruction reveals how the press has discursively participated in the language policy development process with regard to PMI in Hong Kong. The results remind policy actors of the importance of framing and counter-framing when engaging with the mass media in the educational language policy debate.

The last two studies in this special issue cover the challenges of implementing mother tongue education in the Philippines and the national language policy implementation at the institutional level in Viet Nam. Metila, Pradilla, and Williams draw on a nationwide survey to report on the challenges in implementing mother tongue education in linguistically diverse contexts such as the Philippines. A variety of challenges such as the organization and teaching of classes in contexts where a range of mother tongues are spoken were identified in the survey, which require policymakers and implementers to localize the relevant national language policy so that students' educational outcomes could be improved in the complex, dynamic multilingual settings. Tran, Kettle, and May demonstrate how the Vietnamese national Project 2020 language policies are mediated to have different impacts on teachers' micro-level classroom practices in different types of higher education institutions (i.e., public and private ones). As teachers in the non-public sector become much more proactive in responding to student needs and supporting their learning, a growing feature of marketized higher education in Vietnam, they also generate the need for public universities to improve working conditions and teachers' practices so that policy-makers and teachers together can realize the country's English language policy objectives.

\section{Conclusion}

The studies in this special issue not only articulate the significant conceptual and methodological implications of language policies, but they are also expected to generate practical suggestions for both language policy-makers and language educators who have to deal with complex language issues. Language policy-makers in East Asian and other contexts will benefit from this special issue as it is likely to help develop a much better understanding of critical issues involved in language policy formulation, development, and implementation in light of intensified global engagement, migration, and socio-cultural shifts. These may include contextual realities they may need to consider, the ways to persuade the public to respond positively to particular policies, the need to adopt a consensusoriented policy-making by involving the public, and the likely implications that particular policies have for the community (means to redress some of the negative impacts). This special issue expects to help language educators in East Asian and other contexts negotiate with language policy-makers and education administrators more 
effectively. We hope that results of these studies shall empower language educators with appropriate knowledge to engage with policy-makers and provide feedback to them so that particular policies could be refined for implementation.

Acknowledgments The writing of this editorial is generously supported by a Research Grant on "Language policy and the mass media in Hong Kong, Guangzhou and Arizona" from the Research Grants Council of the Hong Kong Special Administrative Region, China (RGC Ref No. HKU 17402414H). The editing of this special issue is supported by an Oriental Scholar Visiting Professorship from Shanghai Municipal Government.

\section{References}

Block, D., \& Cameron, D. (Eds.). (2002). Globalization and language teaching. London: Routledge.

Gao, X. (2012). Cantonese is not a dialect: Chinese netizens' defence of Cantonese as a regional lingua franca. Journal of Multilingual and Multicultural Development, 33(5), 449-464. doi:10.1080/ 01434632.2012 .680461

Gao, X. (2015). The ideological framing of 'dialect': An analysis of mainland China's state media coverage of 'dialect crisis' (20022012). Journal of Multilingual and Multicultural Development, 36 , 468-482. doi:10.1080/01434632.2014.943234.

Gao, X. (In press). Linguistic instrumentalism and national language policy in Mainland China's state print media coverage of the 'Protecting Cantonese Movement'. Chinese Journal of Communication, 1-19. doi: 10.1080/17544750.2016.1207694.
Heller, M., \& Martin-Jones, M. (Eds.). (2001). Voices of authority. Education and linguistic difference. Westport, CT: Ablex Publishing.

Lo Bianco, J., Orton, J., \& Gao, Y. (Eds.). (2009). China and english: Globalisation and the dilemmas of identity. Bristol, UK: Multilingual Matters.

Park, J. S., \& Wee, L. (2012). Markets of English: Linguistic capital and language policy in a globalizing world. New York: Routledge.

Pérez-Milans, M. (2015). Language education policy in late modernity: (Socio) linguistic ethnographies in the European Union. Language Policy, 14(2), 99-107. doi:10.1007/s10993-014-9354-7.

Piller, I., \& Cho, J. (2013). Neoliberalism as language policy. Language in Society, 42, 23-44. doi:10.1017/S0047404512000887.

Shao, Q., \& Gao, X. (in press). 'Noisy guests shall not unseat the host': Framing high-stakes English examinations in mainland China's state-controlled print media. English Today, 1-6. doi: $10.1017 / \mathrm{S} 0266078416000419$.

Tollefson, J. W. (Ed.). (2012). Language policies in education: Critical issues (2nd ed.). New York: Routledge.

Tollefson, J. W., \& Tsui, A. B. M. (Eds.). (2004). Medium of instruction policies: Which agenda? whose agenda?. Mahwah, NJ: Lawrence Erlbaum Associates.

Wang, W. (2015). Teaching English as an international language in China: Investigating university teachers' and students' attitudes towards China English. System, 53, 60-72. doi:10.1016/j. system.2015.06.008.

Wee, L. (2011). Language without rights. Oxford: Oxford University Press.

Yan, Y. (2010). The Chinese path to individualization. British Journal of Sociology, 61, 489-512. doi:10.1111/j.1468-4446.2010.01323.x.

Yang, C., \& Zhang, L. J. (2015). China English in trouble: Evidence from dyadic teacher talk. System, 51, 39-50. doi:10.1016/j. system.2015.03.008. 